\title{
Customer Perception of Green Advertising in The Context of Eco-Friendly FMCGs
}

\author{
Rumman Hassan \\ University of Southern Queensland \\ E-Mail: Rumman.Hassan@usq.edu.au \\ Fredy Valenzuela \\ University of New England \\ E-Mail: fvalenz2@une.edu.au
}

\begin{abstract}
Past studies have focused on the role of advertising in consumer behaviour. However, with the emergence of green marketing as a field of study, there is a growing importance in eco-friendly products. The present study contributes to the literature on green marketing by investigating Australian customers' exposure to and trust in green advertising in the context of eco-friendly Fast Moving Consumer Goods. In addition, the study investigates whether customers' purchase intentions are influenced by such advertisements. The present study, which includes in-depth interviews, gives an insight into issues relating to green advertisements. The findings provide a detailed insight into the variation in terms of customers' perceptions of green advertising and its influence on customers. Findings and discussion are presented.
\end{abstract}

Keywords: Green marketing, Green products, Green advertising, Fast Moving Consumer Goods, Trust

\section{INTRODUCTION}

Environmental issues have attracted much attention around the world. Australia is no exception. In 2007-2008, 82 \% of Australian adults reported that they were concerned about at least one environmental problem. However, only $26 \%$ reported that the condition of the natural environment was bad while almost $39 \%$ had no opinion. Despite this, $53 \%$ of the adult population opined that the natural environment was declining (ABS, 2010). 
In light of the growing importance of environmental issues, the marketplace has seen the proliferation of eco-friendly products. Green advertising plays a major role in the marketing of these products. The purpose of this study is to explore consumers' perceptions of green advertisements in the context of Fast Moving Consumer Goods (FMCGs).

The paper has been organised into sections. The literature review presents a critical analysis of the work done in this area and presents the research question to address the gaps in the literature. Following that is a discussion of the methodology used for the study and the rationale for the selection of the methodology. The findings of the indepth interviews along with some excerpts are followed by a discussion of the implications of these findings. Finally, the limitations of this research are addressed.

\section{LITERATURE REVIEW}

Shimp (2003) defines advertising as “nonpersonal communication that is paid for by an identified sponsor, and involves either mass communication via newspapers, magazines, radio, television, and other media (e.g., billboards, bus stop signage) or direct-to-consumer communication via direct mail” (p. 413). Advertising is said to play several roles, such as providing information, persuading customers, reminding them, and reinforcing positive beliefs that they may have about certain brands. Rahbar and Wahid (2011) state that the primary goal of green advertising is to try to alter consumers' traditional purchase behaviour by making them buy products that either do not harm the environment or that have a positive impact on it environment. This notion was reinforced by Akherst, Alfonso and Goncalves (2102) who stated that whenever there is a purchase decision, there is a potential that the final decision can lead to a sustainable pattern of consumption. They emphasised that all buying actions have ethical, resource and community consequences.

Green advertising promotes green products and informs customers of their environmental benefits. Their objective is to influence consumers' purchase behaviour by encouraging them to buy environmentally friendly products and to direct their attention to the positive consequences for themselves and for the environment of their purchase behaviour (Rahbar \& Wahid, 2011). Since advertising both creates awareness and it a means of persuasion, it must be studies to see how it affects the purchase intention of consumers for green products.

In “Strategic Green Marketing,” McDaniel and Rylander (1993) developed a tenpoint plan of on how to incorporate green marketing into marketing strategy development. In the ninth step, they highlight that companies, through effective advertising and publicity, need to communicate with customers as to what they are 
doing on the green marketing front. Such communication will not only build customer loyalty towards the company but will also encourage customers to cooperate with the company's environmental efforts.

The importance of green advertising has also been highlighted by Pickett-Baker and Ozaki (2008) who found that aside from cleaning products, most customers could not identify greener products. This was probably because most green message labels did not make an impression in buyers' minds (Green Biz Staff, 2009). Thus, communication is an area of weakness for green marketers (Juwaheer, Pudaruth \& Noyaux, 2012). Carlson et al. (1993) have affirmed a parallel rise in environmental advertising accompanied by increased consumer interest in the environment. Advertising terms such as "recyclable, environmentally friendly, ozone safe, biodegradable" are regularly seen in green advertisements and consumers are often exposed to such messages (D'Souza, 2005).

The importance of advertising as a green marketing tool has been noticed by many scholars and is a topic of emerging research. In a study of the green advertising practice of international firms, Leonidou, Palihawadana, and Hultman (2011) analysed the trend of green advertising practices of firms over the past 20 years. Findings revealed that a total of 195 firms were the sponsors of the 473 advertisements. The top ten companies were responsible for $38.3 \%$ of these advertisements. Most of the sponsors of green advertisements were firms located in the developed parts of the world, such as Europe, the US and Japan, and manufacturing firms constituted $93.4 \%$ of the sponsors of green advertisements.

D'Souza and Taghian (2005) studied the effects of green advertising on attitudes and choice of advertising themes in Victoria, Australia. In their study, customers were categorised according to their degree of involvement. The study analysed the cognitive and affective responses of these two groups to various green advertising themes. Results of the study showed that customers with less involvement appeared to have greater disregard for green advertising across all the perceptive measures towards green advertising. This finding has implications for manufacturers of convenience items such as FMCGs, which are predominantly low-involvement products. It will be interesting to investigate if green advertising influences the purchase intentions of customers in the case of eco-friendly FMCGs.

The relationship between green marketing tools (eco-brand, eco-label, and environmental advertisement) and consumers' purchase behaviour was examined by Rahbar and Wahid (2011). They hypothesized that a significant positive relationship exists between environmental advertisement and customers' actual purchase behaviour. However, the findings showed no significant relationship between environmental 
advertisements and actual purchase behaviour. These findings somewhat concur with the findings of D'Souza and Taghian (2005) that green advertising had little role in the purchase of low-involvement products. In a research project conducted in Bangladesh, Islam, Hassan and Hossain (2011) found a positive relationship between environmental attitude and involvement with green advertising. The study reveals that, since Bangladesh is regularly ravaged by natural disasters such as floods and cyclones, people tend to focus on advertisements with environmental messages.

In Australia, real household final consumption expenditure per capita increased at an average annual rate of 2.0\% between 1985-1986 and 2005-2006. In 2005-2006, 46\% of all household final consumption expenditure went to rent and other dwelling services, food, catering, and transport. From the perspective of FMCGs, food and personal care items are relevant to this research. In terms of food, there was a total increase of $7.8 \%$ with a low average annual increase of $0.4 \%$ during the period in per capita real household final consumption expenditure on food and non-alcoholic beverages. In terms of personal care items, there was a total increase of $72.3 \%$, an annual average increase of $2.8 \%$ (Australian Bureau of Statistics, 2010). Although the increase in food consumption was slight, the significantly higher increase in consumption of personal care items indicates households' rapidly growing demand for FMCGs. Given this increase in domestic household expenditures, and the relationship between consumption and environmental consequences, it is important to investigate consumers' intentions to purchase eco-friendly products.

This led to the development of three major research questions. The first two questions explore Australian customers' exposure and trust in green advertising. The third question refers to the impact of green advertising on customers' purchasing behaviour. Individuals with greater knowledge of environmental issues and problems seemed more active in environmental issues than were people with less knowledge (Stern, 1992); hence this investigation aimed at determining if green advertising would increase customers' knowledge of green products and their preference for green products.

RQ1: What is the level of exposure of Australian customers to green advertising in the context of FMCGs?

RQ2: What is the level of trust of Australian customers in green advertising in the context of FMCGs?

RQ3: Does green advertising influence Australian customers' purchase intentions in the context of FMCGs? 


\section{METHODOLOGY}

Twenty-seven shoppers of various ages, occupations, ethnic backgrounds, and socio-economic status were interviewed at retail outlets in Sydney. . The mall intercept method was used to select the respondents. Twelve of the respondents were males, and 15 were females. The diversity of respondents provided the researcher with different perspectives and insights into the mindset of the consumers. People were interviewed until a convergence of opinions began to appear. Strauss and Corbin (1990) have suggested that researchers should continue qualitative focused interviews until reaching repetition and saturation. The similar themes that arose from the respondents' responses in the qualitative phase of the research became the factors to be measured using a quantitative survey. Convergence in the responses began to occur at the 20-interview mark. In order to be on the safe side, the researcher conducted an additional seven interviews to ensure that no new information would be forthcoming. Travers (2000) considered a sample size of 27 as optimum and appropriate given time needed to collect, transcribe, and analyse data. Bauer and Gaskell (2000) argue that more interviews do not necessarily translate into a better quality or more detailed understanding of a phenomenon. Sandelovsky (1995) argues that sample size of qualitative studies is primarily a matter of judgment and experience in evaluating the quality of information collected against the uses of that information.

The interviews followed a conversational rather than an interrogative style, as recommended by Minichielo et al. (1999). The main task of the interviewer was to encourage respondents to reveal insights and provide structure to the discussions to increase coherence and meaningfulness. Despite the conversational style, semistructured questions allowed the researcher to maintain focus on the topic and the appropriate pace and flow of the interview. Each interview was recorded using a digital recorder. These recordings were later stored in MP3 format on a computer hard drive. In addition, the researcher diligently took field notes during each interview, which were referred to later during data analysis.

The respondents were comfortable with the questions and had no difficulty understanding them. The average interview lasted approximately 22 minutes.

Before analysing the interview data, the researcher transcribed the interviews verbatim. Each interview was listened to several times to gain a greater sense of the whole interview. Once the transcription was completed, the researcher used MAXQDA version 10, a sophisticated text analysis software, to aid in the analysis of the data. The researcher also read the transcripts of the interviews several times to achieve greater familiarity with the content before commencing with the coding task. 
The analysis performed at this stage was quite rigorous and was conducted by inductive reasoning methods (Lincoln \& Guba, 1986). Each of the transcribed interviews was imported from MS Word. Separate sections were created for the each question. Once this was done, each response was analysed, using inductive reasoning (Lincoln \& Guba, 1986), for the presence of dominant and, at times, not so dominant themes. Responses to certain questions were homogenous across most of the respondents, others were unique. Each response was classified and coded. Similar themes were clustered. After this, similar responses were aggregated to give a frequency to responses that could be classified as being the same. This gave the researcher a clear understanding of the different references made and the number of references made to enable a presentation of responses in a tabular format.

The University of New England (UNE) Human Research Ethics Committee (HREC) granted approval for the conduct of the project with approval number HE11208. Ethics approval was granted on the basis of submission of background and aims of the research to be undertaken, and a preliminary draft of the questions to be asked during the qualitative interviews.

\section{FINDINGS}

Since advertising is one of the most effective ways for companies to communicate their offering to customers, and since its importance has been emphasized in the literature (Ackerberg, 2001; Deighton, Henderson, \& Neslin 1994; Gotlieb \& Sarel, 1992), the researcher found it necessary to investigate how consumers perceive green advertising and its influence on the decision-making process of Australian customers. As mentioned in the methodology section, in-depth interviews were carried out in order to answer the research questions. The participants' responses could be classified along three dimensions that emerged from the interviews: two pertained to the first research question and the one to the second. Firstly, the issue of exposure related to the number of people being exposed to and noticing these ads. Secondly, trust was related to the credibility of the information being communicated. Finally was the impact of these adverts on customers' decision making and purchase intentions in the context of ecofriendly FMCGs. What follows is a discussion of the major themes that arose from the interviews.

\section{Exposure to Green Advertising}

It was noted that $22.2 \%$ of the respondents revealed that they rarely notice green advertisements. This was attributed to lack of interest or switching television channels when such advertisements were shown. According to some respondents, such 
advertisements and the notion of eco-friendly products were modern-day hype and not worth paying attention to. The following responses express these sentiments.

Considered such advertisements to be all hype:

- No, because it's all hype. If I see something and it seems interesting, I try it and if I like it I'll buy it again (Respondent 18).

Not enough of such type of advertisements:

- I seldom see because there isn't much. There should be more (Respondent 26).

Does not pay attention to advertisements in general:

- I'm not very exposed to advertising. I don't read magazines and papers very much. I generally watch the ABC. If it is going to come on my radar it's probably going to have to be displayed at the store. I'll probably go "oh that's a new thing" and have a look at it then. And probably my scepticism will grow as there is more of it as they start using it more as a marketing tool. Then I will start thinking, "are the claims really true? (Respondent 11).

\section{Trust in Green Advertising}

The findings showed that $44.4 \%$ of the respondents vehemently stated they did not trust green advertisements at all. As noted earlier, there have been several responses pertaining to the lack of trust customers have in the eco-friendly claims made by companies. The responses obtained from the interviewees in this section were no different. The customers who did not trust green advertisements firmly believed that the claims being made were false, fabricated and not substantiated. They also believed that such claims were nothing more than a modern-day marketing ploy on the part of the companies. Following are some of the quotes.

- No I don't trust those ads. I think they are made from a marketing point of view only to sell more items' (Respondent 25)

- I don't believe them. I don't trust them at all, but what proof do they have? Everybody will claim that it is environmentally friendly, but how do you verify that statement? Unless there is a proof that they provide' (Respondent 27)

- I'm deeply suspicious of them actually. I don't want to be manipulated. If somebody tell me you've got to buy this because it is good for the environment, I want to say tell me collectively, "how me buying that is actually going to be good for the environment?". And often it is quite difficult to prove (Respondent 13)

- I think unfortunately I tend to be a bit of a cynic when I see them because I think this is where it is almost like "I'm a green product, so I can charge twice as 
much as anything else”. So I tend to get a little bit cynical. So do I believe all the claims in the advertising? No. I try to make a best judgment call of my own and sometimes that is making a wrong judgment call because everyone that says green is not always green. And you kind of think "if you're spending so much money on green advertising, are you in fact green because you're spending so much money”. So a bit cynical (Respondent 23)

- I think a good percentage of them would be false. Maybe not false, but misleading (Respondent 12)

Results also show that $14.8 \%$ of the respondents reported trusting the messages in ads for eco-friendly products. These respondents expressed a positive view of these advertisements and deemed them to be reliable and credible sources of information. Following are some of their responses.

- I do in a sense, but in a way everyone is trying to get some sort of accreditation like the heart tick approval (Respondent 19)

- We do (trust the advertisements) (Respondent 5)

- Well I trust because I am eager. I am eager to know much about environmental friendly products (Respondent 4)

\section{Influence of Green Advertising on Australian Customers’ Purchase Intentions}

Among the respondents, 29.6\% reported that they were influenced by advertisements of eco-friendly products. The interesting finding from the response to this question was that customers who already shown high levels of awareness of and empathy towards environmental issues were influenced by such advertisements. These responses were highly optimistic of the benefits of eco-friendly products and the respondents had genuine trust in the claims made by the manufacturers and marketers of those products. Following are some of the responses from these respondents.

- Yup (influenced by green advertisements). Take a look at all the lightings in my house (referring to energy saving bulbs) (Respondent 6)

- I am persuaded by them. Maybe because I am not a critical thinker. It all depends on the advertising. Some advertising is cleverer. Sometimes I will buy the product, but if I'm not happy I will not buy it again. But yes, I'm swayed towards natural products (Respondent 9)

- I am persuaded by them. As an environment student who has a BSc in Environmental Studies, I do look at them in a different way but it's not that they always attract my attention (Respondent 16). 
It was noted that $25.9 \%$ of the respondents were not influenced by advertisements of eco-friendly products. These sceptical respondents had little or no trust in the claims made by such advertisements. These responses reinforced the finding that there was not only a lack of green advertising, but also scepticism about green products. Following are some of the responses from these respondents.

- Not really. No in terms of groceries, but there are other products like Prius and cars and big ticket products which I say I would be. But when it comes to groceries, not really (Respondent 19)

- I'm not persuaded by them (Respondent 18)

- No [not influenced] unless the pricing is good (Respondent 27).

It was noted that $22.2 \%$ of the respondents stated that they were sceptical, but sometimes influenced by green advertisement. These respondents paid attention to the advertisements but tended to use their own judgment to gauge the credibility of the advertisements and then make their decision. Following are some of their responses.

- Most advertising is going to be swayed about what they want you to know. So with most advertising there is a level of credibility and a level of scepticism. Depending on what they say makes sense or is illogical. If it's not sensible or illogical, I discount it (Respondent 2)

- I guess I'm guessing a bit sceptical. Not because I want to, but there have been some incidents where tests have shown later on that they are not as eco-friendly or as healthy or as natural as what we were initially led to believe (Respondent 7)

- Not always. But I would expect if they are coming from a big company they would have to get it right (Respondent 21).

It was also observed that $7.4 \%$ of the respondents were undecided when asked about eco-friendly advertising. These respondents were undecided about how they viewed the issues of green products and green marketing.

\section{DISCUSSION AND CONCLUSION}

This study took a holistic look at how customers perceive advertisements of ecofriendly FMCGs. The study focused on two broad research questions, which aimed at unearthing an insight on how Australian customers perceived advertisements of this nature and the influence of green advertising on their purchase intentions. In light of the research questions, three themes came to surface during the interviews: exposure, trust, and influence. 
About 20\% of the respondents had not been exposed to advertisements for ecofriendly products. This lack of exposure was attributed to the respondents' lack of interest in eco-friendly products. Based on the findings of the interviews which state that some respondents do not find the advertisements interesting, that there are not enough of them, and they are more hype than anything else, it is suggested that businesses need to find ways to refute these beliefs. They can do so by making the advertisements more interesting. In addition, the advertisements need to be relevant to the lives of the audience. Being able to identify with the advertisements will most likely encourage more people to watch these advertisements. This implies that companies and advertising agencies need to pay more attention to the message strategy by being more creative in designing their messages. The use of strategies such as the slice of life will encourage people to see themselves in the ads.

The issue of trust was another important factor that came into light in the interviews. This issue reinforced the issue of green trust which was introduced in modern green marketing literature by Chen (2010) and later elaborated upon by Chen and Chang (2102). The respondents were divided into distinct groups depending on their level of trust. Around $15 \%$ of the respondents had complete trust on these advertisements and the messages they conveyed. However, an overwhelming 44\% of the respondents had none. Of those who trusted these advertisements, some wanted some sort of accreditation on the products to confirm their trust in the claims made by the product. And those who expressed complete trust in the products and in the claims made in the advertisements claim to do so because they are hard core loyals of ecofriendly products or re at least interested in the benefits of using such products.

The overwhelming majority of respondents who did not trust green advertisements believe that the claims being made by such advertisements were either false or exaggerated. This suggested that the notion of "greenwashing" as pointed out by Polonsky, Grau, and Garma (2010) was embedded in the minds of the consumers. In respondents' pinion this was nothing more than a marketing ploy that makes customers feel guilty so they will spend more in the hope that they are protecting the environment. This finding suggests that companies must substantiate the claims they make in green advertisements. Demonstrating tangible environmental benefit is of paramount importance if the advertiser and marketers of eco-friendly products want customers to believe the messages conveyed in green advertisements. This finding was consistent with the findings of Gefen and Straub (2004) who noted that customer trust influences purchase intentions.

The interviews also revealed that around 30\% of the respondents were influenced by green advertisements. The analysis of the interview transcripts showed that those 
who were influenced by green advertisements were aware of environmental issues and believed that their actions had an impact on the environment. Consequently, these respondents viewed green advertisements positively, they were eager to learn about ecofriendly products, and had complete faith in the claims made in these advertisements. This implies that there needs to be greater education on environmental matters. The results were in line with the findings of Juwaheer et al. (2012) who found a fairly positive correlation between customers' preference for green advertisements and their green purchase intentions.

In contrast, $25 \%$ of the respondents were not influenced by green advertisements. These respondents claimed that they were not persuaded by green advertisements for products such as FMCGs, but would pay attention to the eco-friendly attributes of highinvolvement items such as motor vehicles. This gave an indication that people viewed the environmental impact of big-ticket items as of greater importance to regular convenience goods. It was also noted that around $20 \%$ of the respondents were sceptical but were occasionally influenced by green advertisements. It was reported that respondents were more likely to be influenced by advertisements coming from wellknown brands since they were expected to be more credible sources of information. The interviews also revealed that around seven percent of the respondents were undecided in their view of green advertisements.

The most important thing that marketers need to do is to increase reach and exposure of the advertisements and enhance the credibility of the messages they convey. The latter is of paramount importance in terms of gaining the trust of the consumers. Providing consumers with evidence of tangible benefits of eco-friendly FMCGs should go a long way in terms of gaining their trust. This confirms the findings of Juwaheer et al (2012) who argue that marketers need to ensure the effectiveness of green advertising in order to encourage customers' greener purchasing patterns by ensuring that the information in the green advertisements is accurate. Once green products are not perceived to cater to a niche and are instead targeted at the mainstream and viewed as the "new normal," manufacturers will be able to secure a larger market share (Rettie, Burchell, \& Barnham, 2014).

\section{LIMITATIONS AND FUTURE RESEARCH DIRECTIONS}

By focussing on consumer perception of eco-friendly advertising, this paper contributes to the literature on green marketing. However, due to its qualitative and exploratory nature, the generalizability of this paper is limited. Further quantitative studies are needed to validate the findings of this study. There is also scope for further qualitative and quantitative research to investigate the relationship between green 
advertising and green product purchase behaviour. Future research could take into account the antecedents of consumers' buying behaviour in the context of green products and look at the role of green advertising in relation to the other factors.

\section{REFERENCES}

Ackerberg, D. A. (2001). Empirically distinguishing informative and prestige effects of advertising. RAND Journal of Economics, 32(2), 316-333. http://dx.doi.org/10.2307/2696412

Akehurst, G., Afonso, C., \& Goncalves, H.M. (2012). Re-examining green purchase behaviour and the green consumer profile: new evidences. Management Decision, 50(5), 972-988. http://dx.doi.org/10.1108/00251741211227726

Australian Bureau of Statistics (2010). “ABS Social Trends”. Retrieved October 10, 2014, from http://www.abs.gov.au/Ausstats

Bauer, M., \& Gaskell, G. (2000). Qualitative research with text, image and sound. London: Sage Publications Inc. http://dx.doi.org/10.4135/9781849209731

Carlson, L., Grove, S., \& Kangun, N. (1993). A content analysis of environmental advertising claims: a matrix method approach. Journal of Advertising, 22(3), 2740. http://dx.doi.org/10.1080/00913367.1993.10673409

Chen, Y.S. (2010). The drivers of green brand equity: Green brand image, green satisfaction, and green trust. Journal of Business Ethics, 93, 307-319. http://dx.doi.org/10.1007/s10551-009-0223-9

Chen, Y., \& Chang, C. (2012). Enhance green purchase intentions - The roles of green perceived value, green perceived risk, and green trust. Management Decision, 50(3), 505-520. http://dx.doi.org/10.1108/00251741211216250

D’Souza, C. (2005). Green advertising effects on attitude and choice of advertising themes. Asia Pacific Journal of Marketing and Logistics, 17(3), 5166. http://dx.doi.org/10.1108/13555850510672386

D'Souza, C., \& Taghian, M. (2005). Green advertising effects on attitude and choice of advertising themes. Asia Pacific journal of Marketing and Logistics, 17(3), 51-66. http://dx.doi.org/10.1108/13555850510672386

Deighton, J., Henderson, C. M., \& Neslin, S. A. (1994). The effects of advertising on brand switching and repeat purchasing. Journal of Marketing Research, 31(1), 2843. http://dx.doi.org/10.2307/3151944

Gefen, D., \& Straub, D. W. (2004). Consumer trust in B2C e-commerce and the importance of social presence: Experiments in e-products and e-services. Omega, 32(6), 407-424. http://dx.doi.org/10.1016/j.omega.2004.01.006 
Gotlieb, J. B., \& Sarel, D. (1992). The influence of type of advertisement, price, and source credibility on perceived quality. Journal of the Academy of Marketing Science, 20(3), 253-260. http://dx.doi.org/10.1007/BF02723412

Green Biz Staff (2009). “Most green labels fail to catch shoppers’ eyes, survey finds”. Retrieved August

12 , 2015, from http://www.greenbiz.com/news/2009/09/23/most-green-labels-missingmark-survey-finds

Islam, M. S., Hassan, R., \& Hossain, M. M. (2011). An assessment of the impact of green messages on the audience of Dhaka city. East West Journal of Social Studies, 2, 21-38.

Juwaheer, D. T., Pudaruth, S., \& Noyaux, M.M.E. (2012). Analysing the impact of green marketing strategies on consumer purchasing patterns in Mauritius. World Journal of Entrepreneurship, Management and Sustainable Development, 8(1), 36-59. http://dx.doi.org/10.1108/20425961211221615

Leonidou, L. C., Leonidou, C. N., Palihawadana, D., \& Hultman, M. (2011). Evaluating the green advertising practices of international firms: A trend analysis. International Marketing Review, 28(1), 6-33. http://dx.doi.org/10.1108/02651331111107080

Lincoln, J. R., \& Guba, E. G. (1985). Naturalistic Inquiry. Beverly Hills: Sage. http://dx.doi.org/10.1016/0147-1767(85)90062-8

McDaniel, S. W., \& Rylander, D. H. (1993). Strategic green marketing. The Journal of Consumer Marketing, 10(3), 4-10. http://dx.doi.org/10.1108/07363769310041929 Minichielo, V., Madison, J., Hays, T., Courtney, M., \& St-John, W. (1999). Handbook of Research Methods for Nursing and Health Science. French Forest, NSW: Pearson Education Australia.

Pickett-Baker, J., \& Ozaki, R. (2008). Pro-environmental products: marketing influence on consumer purchase decision. Journal of Consumer Marketing, 25(5), 281-93. http://dx.doi.org/10.1108/07363760810890516

Polonsky, M. J., Grau, S. L., \& Garma, R. (2010). The new greenwash? Potential marketing problems with carbon offsets. International Journal of Business Studies, 18(1), 49-54.

Rahbar, E., \& Wahid, N. A. (2011). Investigation of green marketing tools' effect on consumers' purchase bhaviour. Business Strategy Series, 12(2), 73-83. http://dx.doi.org/10.1108/17515631111114877

Rettie, R., Burchell, K., \& Barnham, C. (2014). Social normalisation: Using marketing to make green normal. Journal of Consumer Behaviour, 13, 9-17. http://dx.doi.org/10.1002/cb.1439 
Sandelovsky, M. (1995). Sample size in qualitative research. Journal in Nursing and Health, 18, 179-183. http://dx.doi.org/10.1002/nur.4770180211

Shimp, T. A. (2003). Integrated marketing communications: Advertising, promotions, and other marcom tools. In J. W. Clahoun (Ed.), Markeitng Best Practices (2nd ed.). USA: Thomson Learning.

Stern, P. (1992). What psychology knows about energy conservation. American Psychologist, 47, 1224-1232. http://dx.doi.org/10.1037/0003-066X.47.10.1224

Strauss, A., \& Corbin, J. (1990). Basics of qualitative research: Grounded theory procedures and techniques. Newbury Park, CA: Sage Publications, Inc.

Travers, M. (2002). Qualitative research through case studies. Thousand Oaks, California: Sage Publications Inc. 